\title{
*Practical Study on the Optical Limiter of KTP Crystal
}

\author{
Raad. Sh. Alnaily, Manar .Lo .Dayekh \\ University of AL-Qadisiyah, Department of Physics, IRAQ \\ E-mail:- Raad .Alnayli@ qu.edu.iq \\ E- mail: - Manar-physics@ yahoo.com
}

Received:-14/11/2017

Accepted:-12/12/2017

\begin{abstract}
: -
In this study; The optical power liming behavior was investigated for the $\mathrm{KTiOPO}_{3}$ crystal by using the laser beam z-scan technique and Nd: YAG CW double frequency $532 \mathrm{~nm}$ for variable powers of (10-85) $\mathrm{mW}$. The threshold powers limiting was $60 \mathrm{~mW}$.The results show that the KTP crystal is a good nonlinear response could be used as a potential material for devices in optical applications.
\end{abstract}

Kay Words: - Optical limiter, potassium Titanyl phosphate $\left(\mathrm{KTiOPO}_{3}\right.$ or KTP) crystal, Nd: YAG CWLaser.

Phisiology Classification QC350-467 


\section{Introduction:}

KTP was first developed in the end of the 1970[3].It got a new attention.Tordjman et al analyzed the crystal structure in details in 1974. Dupont Inc, USA, started to investigate KTP's nonlinear optical as well as its mechanical properties in 1976 [4 ].The KTP is biaxial crystal[5]. The crystal possesses a high

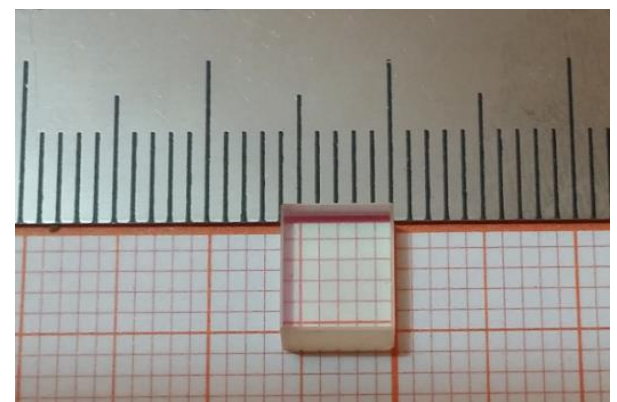

nonlinear, it has a high resistant to optical and mechanical damage, and its transparency range extent from the ultraviolet to the end of the mid-infrared part of the spectrum[4]. KTP has been widely used in various nonlinear optical applications, in particular in the second harmonic generation SHG and optical parametric oscillator OPO devise based on pumping with $1 \mu \mathrm{m}$ radiation from $\mathrm{Nd}$ lasers [6]. KTP crystal is orthorhombic and belong to the acentric point group mm2 [3]. For this point group symmetry class, there are five nonzero nonlinear coefficients, $\mathrm{d}_{15}=6.1 \mathrm{pm} / \mathrm{V}$, $\mathrm{d}_{31}=6.5 \mathrm{pm} / \mathrm{V}, \mathrm{d}_{24}=7.6 \mathrm{pm} / \mathrm{V}, \mathrm{d}_{32}=5.0 \mathrm{pm} / \mathrm{V}$, and $d_{33}=13.7 \mathrm{pm} / \mathrm{V}$ [7] [8] . These values are still considerably higher than for many other nonlinear materials including, $\beta-\mathrm{BaB}_{2} \mathrm{O}_{4}$ and $\mathrm{LiB}_{3} \mathrm{O}_{5}$ [7]. Potassium Titanyl Phosphate (KTP) crystal is nonlinear crystal .The famous type is $\mathrm{KTiOPO}_{4}$.Another type such as
$\mathrm{KTiOPO}_{7}, \mathrm{KTiOPO}_{3}$.All these types are Orthorhombic and belonged to it with only slightly different lattice parameters.

Potassium Titanyl Phosphate $\left(\mathrm{KTiOPO}_{3}\right.$ or KTP) is the most commonly used material for frequency doubling of Nd:YAG and other $\mathrm{Nd}$ : doped lasers, It plays an important role for parametric sources for tenable outputs from visible (600nm) to mid-IR. It is widely used in both commercial and military lasers including laboratory and medical systems, range finders, lidar, optical communication an industrial systems[9].Figure (1) shows the $\mathrm{KTiOPO}_{3}(\mathrm{KTP})$ crystal.

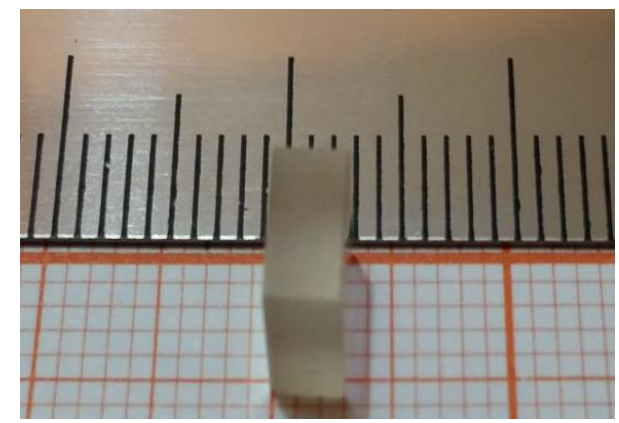

\section{Figure (1) shows the $\mathrm{KTiPO}_{3}(\mathrm{KTP})$ crystal $6 * 6 * 3 \mathrm{~mm}^{3}$}

An optical limiter is a nonlinear optical process in which the transmittance of a material decreases, when increased incident light intensity [2]. The study of the optical limiting (OL) $f$ laser radiation in various materials opens the possibility of using these materials as laser shutters for protection against intense laser radiation and is important in investigating the essential properties of nonlinear optical media [1]. One of the major potential applications of these devices is sensor 
and eye protection [3] .All photonic sensors, including human eye have a threshold intensity above which they can be damaged [4]. By using the suitable materials as optical limiters, allowing them to function optimally to function at higher input intensities [3]. The figure (1) shown the idea of ideal optical limiter has a linear transmittance at low input intensities, but above the threshold intensity its transmittance becomes constant [3].approach the ideal conditions to optimized the performance of the single pure Lithium Triborate crystal (LBO)(The boron-oxygen compound LiB3O5 as a Nonlinear Optical crystal ).as proposal element model for the combination of the Second Harmonics Generation (SHG) and Third Harmonic with fundamental Na:YAG laser $1.064 \mu \mathrm{m}$ and its frequency doubling $533 \mu \mathrm{m} \mathrm{Nd}$ has been treated.[10] [11]. The Optimum cut transversal KDP Q-switches for Nd:YAG lasers has been investigated by R.Sh.Alnayli et al [12].

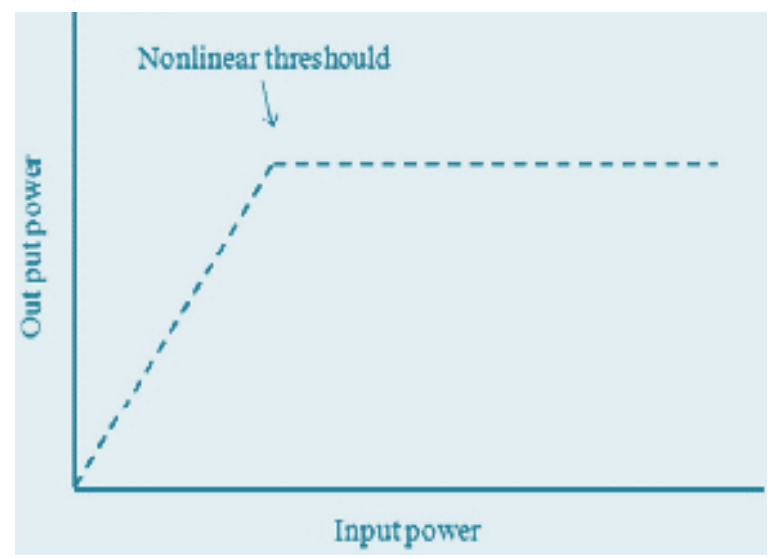

Figure (2-15) idea of ideal optical limiting [77].

\section{Mechanisms types of Optical Limiting}

Optical Limiting can be achieved by means of nonlinear optical mechanisms including, scattering, self- focusing, self- defocusing, two photon absorption, free carrier absorption, and reverse absorption in nonlinear materials [3]. The nonlinear Optical mechanism could be employed for the design and performance of optical limiting devices, which could be classified into types. The first type is an energy spreading and the second is an energy absorption [2] [4]. The limiting function of an energy is based on intensity dependent change is spatial structure of laser beam passing through a nonlinear medium [2]. This type requirement is to place an aperture in front of a detector [5]. At low input intensity levels. This change can be neglected and the whole laser beam can be detected through a property aperture in front of a detector [2]. At high intensity levels, this Change becomes server that only. Small fraction of the transmitted beam can pass through the same aperture and finally detector [2]. In this type of mechanism, the nonlinear refraction that can be employed for optical limiting [5]. The optical limiting effect of refraction nonlinear optical mechanism was induced the self- focusing, self- defocusing, and scattering [3]. The second type of Optical Limiting is based on the intensity - dependent nonlinear attention of the laser energy in a given nonlinear materials, whereas the beam-structure changes is not so important. [2]. We only consider the second type of optical limiting power limiting device, for which the intensity dependent transmission changes in a nonlinearity absorptions material 
is most important [6].In this type of mechanism, the nonlinear absorption that can be employed for optical limiting was induced the two-photon absorption (TPA), Reverse absorption, free carrier absorption (FCA) [3].

\section{Experimental part}

The optical Limiting experiment was performed for $\mathrm{KTiOPO}_{3}$ crystal using continuous wave second harmonic ND: YAG laser of wavelength $-532 \mathrm{~nm}$ and power The laser beam focuses by lens with focal length 15 $\mathrm{cm}$. The Crystal is placed at the position in focal point. To variable the input power used A variable beam splitter (VBS). The input power of the laser beam is varied systematically and the corresponding output power is detected by a power meter.

\section{Result and Discussion}

In a previous experimental study, we made a study for nonlinear KTP crystal by using Z-scan technique laser of a continuous wave length
$1064 \mathrm{~nm}$ and frequency doubler with different powers . From the results that we obtained, the magnitude was $3.59 \times 10^{-14} \mathrm{~cm}^{2} / \mathrm{mW}$ when the wavelength $1064 \mathrm{~nm}$ with their power $35 \mathrm{mw}$ and $3.35 \times 10^{-14,} 3.67 \times 10^{-14} \mathrm{~cm}^{2} / \mathrm{mW}$ for $\mathrm{Nd}$ : YAG frequency double $532 \mathrm{~nm}$ by powers using $80 \mathrm{~mW}$ and $25 \mathrm{~mW}$ respectively. While the nonlinear absorption coefficient was measured using the open aperture z-scan method were 2.71 $x 10^{-3} \mathrm{~cm} / \mathrm{mW}$ at $1064 \mathrm{~nm}$ with power $35 \mathrm{~mW}$ and $4.32 \times 10^{-3}, 4.37 \times 10^{-3} \mathrm{~cm} / \mathrm{mW}$ at the Nd: YAG frequency doubler $532 \mathrm{~nm}$ with powers $80 \mathrm{mWand} 25 \mathrm{~mW}$ respectively.

Table (2): The results of nonlinear optical properties for $\mathrm{KTiOPO}_{3}$ crystal.

\begin{tabular}{|c|c|c|c|c|c|}
\hline $\begin{array}{c}\lambda \\
(\mathrm{nm})\end{array}$ & $\begin{array}{c}\text { Power of } \\
\text { laser(mW) }\end{array}$ & $\begin{array}{c}\Delta \mathrm{T}_{\mathrm{p}-} \\
\mathrm{v}\end{array}$ & $\begin{array}{c}\mathrm{n}_{2} \times 10^{-14} \\
\left(\mathrm{~cm}^{2} / \mathrm{mW}\right)\end{array}$ & $\begin{array}{c}\mathrm{B} \times 10^{-3} \\
(\mathrm{~cm} / \mathrm{mW})\end{array}$ & $\begin{array}{c}\mid \chi^{(3)} \times \times \\
10^{-3} \\
(\mathrm{esu})\end{array}$ \\
\hline 1064 & 35 & 9.8 & 3.59 & 2.71 & 2.55 \\
\hline 532 & 80 & 7 & 3.67 & 4.32 & 2.28 \\
\cline { 2 - 6 } & 25 & 2 & 3.35 & 4.37 & 2.32 \\
\hline
\end{tabular}

Nd: YAG laser CW at frequency doubler 532

In this study we made a study to optical power limiter for Potassium Titanyl Phosphate KTP crystal by the use z-scan technique and $\mathrm{nm}$ with power rang (10-85). The figure (2) represent the optical power limiter. It is observed from this figure that KTP crystal occurs a good optical power limiter. 


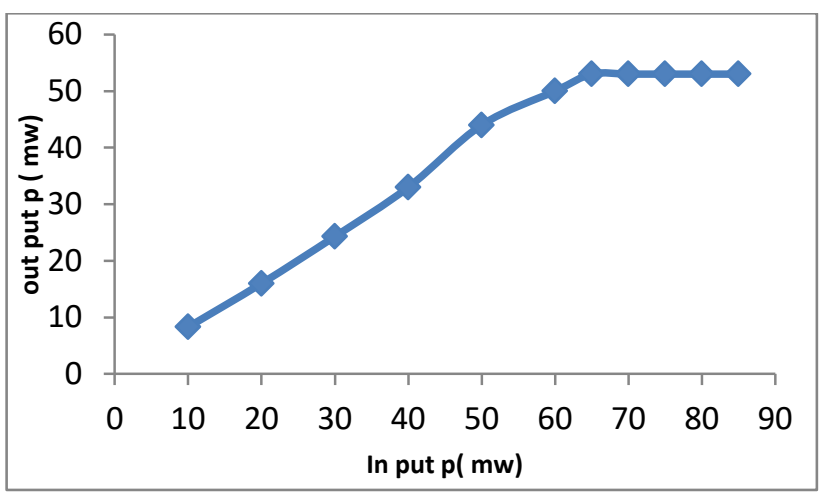

Figure (2) The Optical Limiting for $\mathrm{KTiOPO}_{3}$ crystal.

In figure (2)shows the input power is in the range (10-20-30-40-50 -60-65-70-75-80-85) $\mathrm{mw}$.the output beam power increases with increases input beam power for KTP crystal ,up to $60 \mathrm{mw}$ the output beam power is constant, because its nonlinear absorption coefficient increases with increases in the incident irradiance. The volume of limiting threshold for $\mathrm{KTiOPO}_{3}$ crystal is found $60 \mathrm{mw}$.

Result that KTP crystal is good for Optical Limiter. To obtain on other representation for optical power limiter, we draw transmittance laser beam (output power/ input power) on the expense input laser beam power to crystal, as it is shown in the following figure (3).

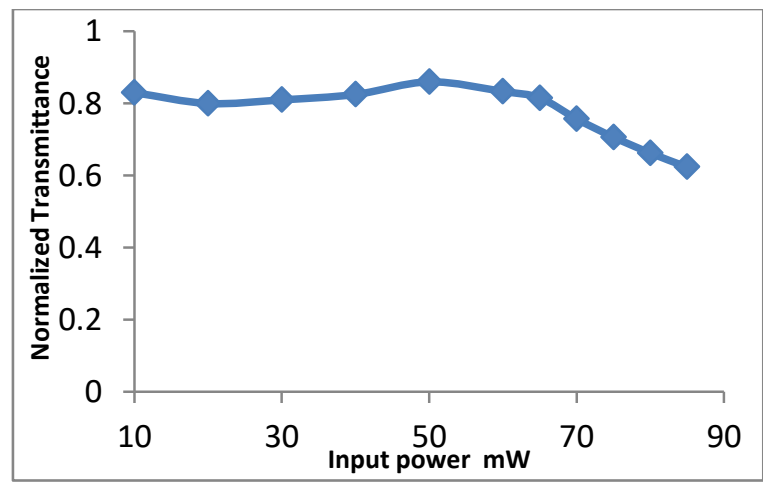

Figure (3) the transmittance curve via input power for $\mathrm{KTiOPO}_{3}$ crystal.

The values optical limiter for $\mathrm{KTiOPO}_{3}$ crystal listed in table (1).

Table (1) the value of the power-limiting threshold.

\begin{tabular}{|c|c|c|}
\hline crystal & $\lambda(\mathrm{nm})$ & $\begin{array}{c}\text { Power Limiting } \\
\text { Threshold } \mathrm{L}_{\mathrm{m}} \\
(\mathrm{mw})\end{array}$ \\
\hline KTP & 532 & 60 \\
\hline
\end{tabular}

\section{Conclusion}

We have investigated the optical power behavior for KTP crystal by using scan beam laser .good optical limiting action with relatively low limiting threshold. our results show that the KTP crystal is promising matter for applications in optical devices .At the study of the power limiting, it is found that KTP crystal possesses a limiting threshold values.

\section{Acknowledgement:}

We are very grateful for professor Dr.Khawla J.Tahir and her fellows in Physics Dept., Karbala University for available techniques scientific discussion.

\section{Reference}

[1]- Rashid A.Ganeev, "Nonlinear Optical Properties of Materials", Springer Book, New York,2013.

[2]- Guang S.He "Nonlinear Optics and Photonics", First Edition, Oxford, 2015.

[3]-Daniela Marciu,"Optical Limiting and Degenerate Four - Wave Mixing in Novel 
Fullerenes" Doctor of Philosophy .Blacksburg, Virginia, 1999.

[4]- Viatcheslav Vanyukov " Effects of Nonlinear Light Scattering on Optical Limiting in Nano carbon Suspensions", Publications of University of eastern Finland, Dissertation in Frosty and national Science Number 182,2015.

[5]- Morvarid Rashdian and Davoud Dorranian, "Investigation of Optical Limiting in Nano materials ", Journal Advanced material SCI, Vol, 2014.

[6]-VENKATRAM, NALLA, "Synthesis and Characterization of Cds Nanoparticles: It's Application to Optical Limiting ", Master of Philosophy, Hyderabad, India, 2004.

[7]- R.W. Munn, C. N. Ironside, "Principles and Application of Nonlinear Optical Materials", First Edition, Springer, 1993.

[8]- F.Z.Henri and S.Cassidy, "Nonlinear optical properties and all optical switching of Congo red in solution", J. Optik, Vol.123, p.711, 2012.

[9]-Potassium Titanyl Phosphate (KTiOPO3 orKTP)crystal,http://www.thatshigh.com/prod ucts_datail/productld=29.html.

[10]- Zahraa S. Shanon ,Raad Sh. Alnayli, Khawla J. Tahir, University Al-Qadisiyah, International Journal of science and Research (IJSR),Vol(5)issue8, pp1683, 2016.

[11]- Zahraa S. Shanon ,Raad Sh. Alnayli, Khawla J. Tahir, University Al-Qadisiyah, International Journal of science and Research (IJSR),Vol(5)issue8, pp1614-1618, 2016.
[12]- Raad Shaker Alnayli,csaba Kuti and J.Baked,Prof." $3^{\text {rd }}$ international symposium on modern optics", Budapest,1,289,1988. 


\section{الخلاصة}

في هذه الدراسة تم بحث سلوك محدد القدرة البصري للبلورة KTiOPO3 باستخدام حزمة الليزر بطريقة المسح وليزر

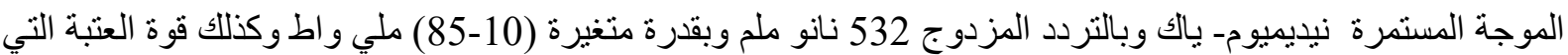

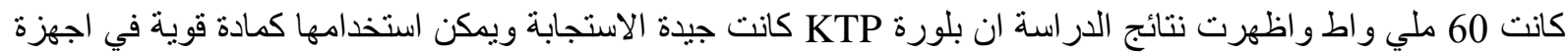

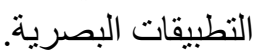

